\title{
Climate Control inside a Greenhouse: An Intelligence System Approach Using Fuzzy Logic Programming
}

\author{
A. Sriraman $^{1 *}$ and R. V. Mayorga ${ }^{2}$ \\ ${ }^{1}$ Department of Engineering, Division of Math. \& Science, Everett Community College, Everett, WA 98201, USA, \\ ${ }^{2}$ Industrial Systems Engineering, Faculty of Engineering, University of Regina, SK, Canada, S4S 0A2
}

\begin{abstract}
Many conventional methods for controlling greenhouse climate are not effective since they are either based on an on-off control method or a proportional control method. As a result, losses in energy, labor, and productivity occur. To maintain a steady climate, an intelligent greenhouse climate controller was designed using fuzzy logic programming. This fuzzy logic program controller is based on the Mamdani controller in MATLAB software. The intelligent controller described in this paper effectively controls factors affecting the greenhouse climate by monitoring and adjusting the thermal system, ventilation-humidification system, thermal shading system, $\mathrm{CO} 2$ generation system, forced ventilation system and performance of system. An interactive graphical user interface was developed to test the controller performance manually. We determined that this intelligent controller is very user friendly, easy to design, highly adaptable, and quick performing, and takes few kilobytes of memory space.
\end{abstract}

Keywords: fuzzy logic program, greenhouse climate controller, intelligent systems approach

\section{Introduction}

The main purpose of a greenhouse is to improve the environmental conditions in which plants are grown. In greenhouses fitted for climate control the environment can be further improved (Ferreira et al., 2002). Computerized greenhouse climate control is employed in places where the climate is extremely harsh and difficult to control manually. Therefore, computerized climate control in greenhouse is inevitable in countries northern hemisphere where the climate is extreme during winter season (Straten, 1999).

The main environmental factors contributing to the greenhouse climate are temperature (Willits and Peet, 1993), relative humidity of the inside air (Körner and Challa, 2003), vapor pressure deficit (Baker, 1990), transpiration (Joliet, 1994; Joliet and Bailey, 1992; Stanghellini and de Jong, 1995) sunlight, $\mathrm{CO}_{2}$ concentration (Willits and Peet, 1989), air movement (Körner and Challa, 2003), and lighting (Willits and Peet, 1993). The computerized climate control functions to maintain a protected environment, despite fluctuations of external climate, and acts as a knowledge database (intelligent rules at program memory space), which can be manipulated by the grower to control their cultivation efforts. (Caponetto et al., 2000). Specifically, the main advantages of using computerized climate control are energy conservation (Papadoupolos, 1991); better productivity of plants (Seginer and Zlochin, 1997); and reduced human intervention (Collewet et al., 1998).

\footnotetext{
* Corresponding author: asriraman@everettcc.edu
}

The proposed greenhouse model has the thermal system, ventilation-humidification system, thermal shading system, $\mathrm{CO}_{2}$ generation system, forced ventilation system and performance of system, as actuators responsible for maintaining a steady climate inside greenhouse. The thermal systems used were heat exchangers laid directly on the ground, fan heater units (Teitel et al., 1999). The ventilation and humidification systems used were natural ventilation, pad cooling, and fog cooling (Seginer and Zlochin, 1997; Seginer et al., 1997). The thermal shade systems used were canvas shade and nets. (Giacomelli and Roberts, 1993; Papadoupolos, 1991; Willits and Peet, 1993). The lighting system used was mini light systems with reflector and ballast integrated in the same metal housing (Willits and Peet, 1993). The $\mathrm{CO}_{2}$ Generator system used was natural gas or propane burners (Willits and Peet, 1989). The forced ventilation system used was mechanical fan (Seginer et al., 1997). The performance system described in this paper is an integral part of the proposed intelligent controller which incorporates the measurement errors of the sensors and adjusts the performance of the actuator system accordingly. The proposed intelligent system controller that senses the inside and outside climate and manipulate the above mentioned actuators to create or maintain an optimal climate inside the greenhouse using a fuzzy logic programming was designed and explained in this paper.

\section{Fuzzy Design vs. Conventional Design}

The approach of conventional design's (Figure 1) first step is to understand the physical system and its control requirements. Based on this understanding, the second step is to 
develop a model, which includes the plant, sensors and actuators. The third step is to use linear control theory in order to determine a simplified version of the controller. The fourth step is to develop an algorithm for the simplified controller. The last step is to simulate the design including the effects of non-linearity, errors, and parameter variations. If the performance is not satisfactory then the system must be remodeled, the controller must be re-designed, the algorithm must be rewritten and then retried.

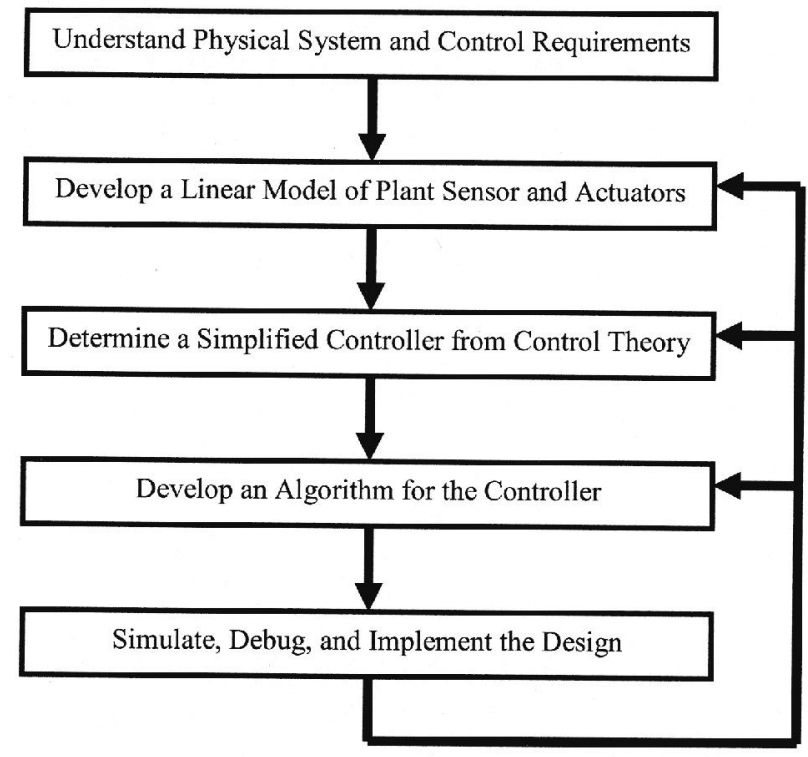

Figure 1. Conventional design.

The approach of Fuzzy logic design's (Figure 2) first step is to understand and characterize the system behaviour by using the knowledge and experience. The second step is to directly design the control algorithm using fuzzy rules, which describe the principles of the controller's regulation in terms of the relationship between its inputs and outputs. The last step is to simulate and debug the design. If the performance is not satisfactory we only need to modify some fuzzy rules and retry.

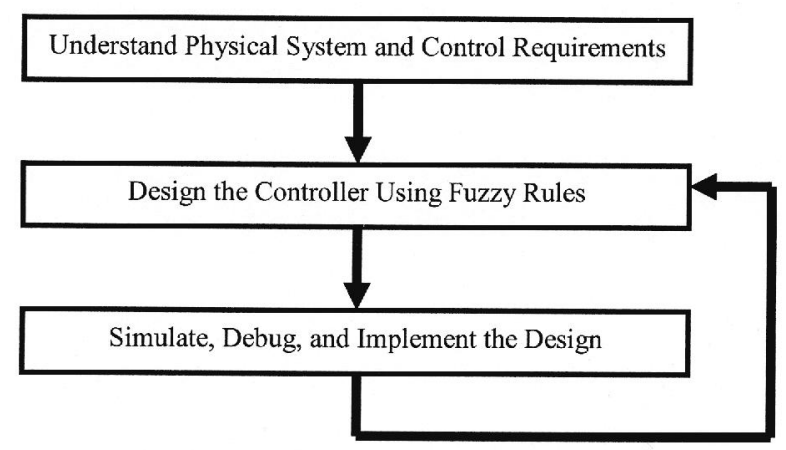

Figure 2. Fuzzy logic design.
Although the two design methodologies are similar, the fuzzy-based methodology substantially simplifies the design loop which results in the following significant advantages: reduces the design development cycle, simplifies design complexity, improves time to market, provides a better alternative solution to non-linear control, improves control performance, simplifies implementation, and reduces hardware costs (Ross, 1995). The factors affecting the climate inside a green-house interact with each other in a complex manner (e.g. temperature and humidity). Therefore, fuzzy logic design can be employed in controlling the climate inside the green house.

\section{Concept of Fuzzy Logic Controller}

The main concept underlying the fuzzy logic controller (Figure 3) comprises four principle components: a fuzzification interface, a knowledge base, decision-making logic, and a defuzzification inference.

The fuzzification interface involves the following functions: measure the values of input variables, performs a scale mapping that transfers the range of values of input variables into corresponding universes of discourse, performs the function of fuzzification that converts input data into suitable linguistic values, which may be viewed as labels of fuzzy sets.

The knowledge database comprises knowledge of the application domain and the attendant control goals. It consists of a "database" and a "linguistic (fuzzy) control rule base". The database provides necessary definitions, which are used to define linguistic control rules and fuzzy data manipulation. The rule base characterizes the control goals and control policy of the domain experts by means of a set of linguistic control rules.

The decision-making logic is the kernel of a fuzzy logic controller. It has the capability of simulating human decisionmaking based on fuzzy concepts, implication and the rules of inference in fuzzy logic.

The defuzzification inference performs the following functions: scale mapping, which converts the range of values of output variables into corresponding universe of discourse; defuzzification, which yields a non-fuzzy control action from an inferred control action; and a defuzzifier which converts an inferred fuzzy control action into a crisp one (Zimmerman, 1990).

\section{Description of Greenhouse with Climate Control System}

An enhanced model of greenhouse designed by Arbel (Arbel et al., 2003) was proposed with additional sensor systems and actuator systems. The enhanced greenhouse model was described in a block diagram as shown in Figure 4 with the description of the sensor systems and actuator systems. The controlling of sensor systems and actuator systems was the primary concern in this project. The geometry of greenhouse which has little importance for the controller point of view was ignored. 


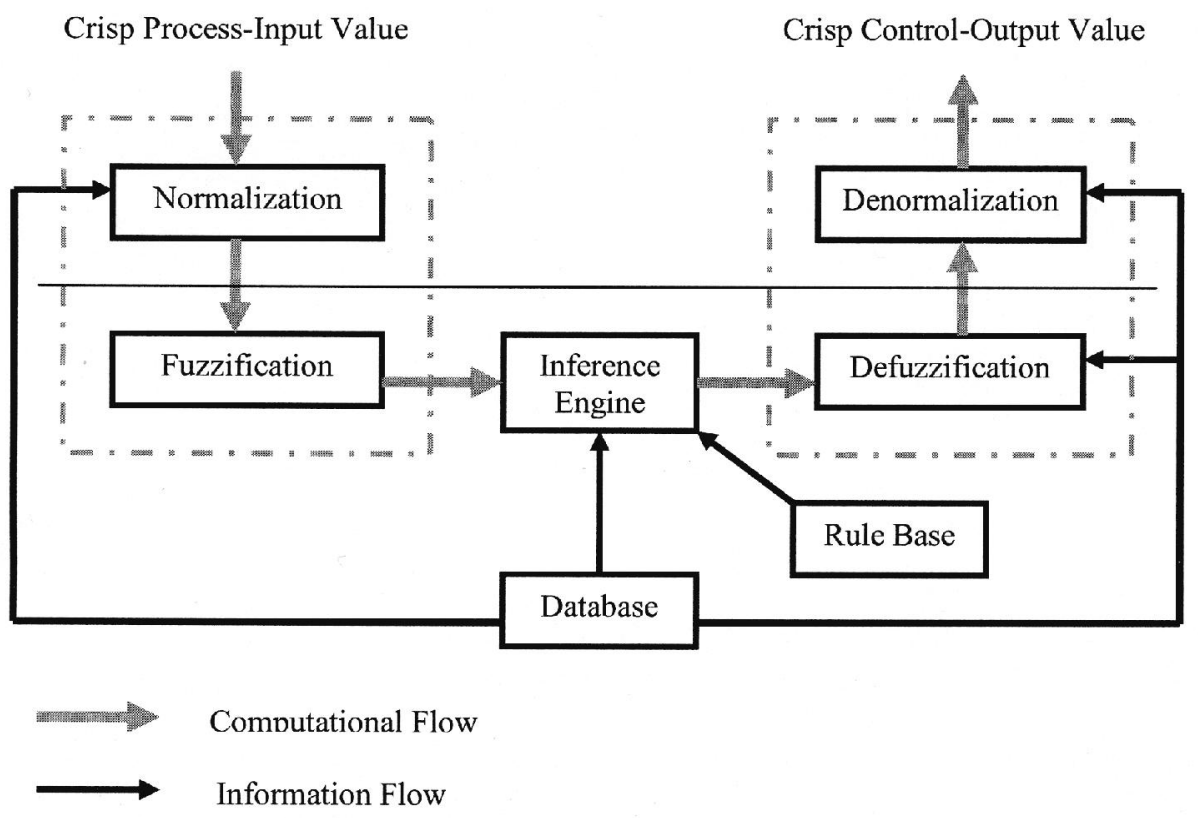

Figure 3. Basic configuration of a fuzzy logic controller.

An enhanced functional block diagram (Figure 5) of climate controller designed by Pasgianos (Pasgianos et al., 2003) was proposed. The enhanced controller was based on feedback-feed forward compensation of external loads on the basis of input output linearization and decoupling; the transformation of user-defined settings for desired climate into feasible controller set points, taking into account of the constraints imposed by the capacities of the actuator systems and the psychrometric laws; and additional outer loops to compensate for model uncertainties and deviations from expected disturbances (climate).

\section{Fuzzy Logic Programming (FLP) in the Intelligent Controller}

The proposed intelligent climate controller used in the climate control of our proposed greenhouse model was based on the intelligent control technique designed by Morimoto \& Hashimoto (Morimoto and Hashimoto, 2000) which consists of a fuzzy controller and two optimizers applied to control of the relative humidity in the storage house and was used for controlling agricultural systems, characterized by complexity and uncertainty, in an elaborate and sophisticated manner. The proposed intelligent climate controller consists of two fuzzy logic programming, where an output from the first fuzzy logic program is given as an input for the second fuzzy logic program and was described in Figure 6.

\section{Design of Fuzzy Logic Program for the Controller}

Fuzzy logic rules were formulated using MATLAB $^{\circledR}$ version 6.0 and the Fuzzy Logic Tool Box, as a simple Mamdani system. Membership functions and rules for the fuzzy inference system were developed by collective knowledge from several books and journals. A block diagram describing the steps in fuzzy logic programming system was shown in Figure 7. The fuzzy logic system includes: fuzzification; rule base; rule evaluation and aggregation system (maximum method) and defuzzification system (mean of maximum method).

\subsection{Inputs, Outputs and Membership Functions of Fuzzy Logic Controller}

The number, limits and shape of membership functions are adjusted using the interactive graphics tools provided by the MATLAB fuzzy toolbox of fuzzy inference editor. The first step in designing the fuzzy logic program was to identify the fuzzy input and output variables with range (universe of discourse). The ten inputs with the range (universe of discourse) used were: (1) Difference in temperature between inside greenhouse and optimum that must be maintained in greenhouse $\left(-10\right.$ to $\left.10^{\circ} \mathrm{c}\right)$; (2) Difference in temperature between outside greenhouse and optimum that must be maintained in greenhouse $\left(-20\right.$ to $\left.20^{\circ} \mathrm{c}\right)$; (3) Difference in relative humidity between inside greenhouse and optimum that must be main- tained in greenhouse (0 to 100\%); (4) Difference in relative humidity between outside greenhouse and optimum that must be maintained in greenhouse (0 to $100 \%$ ); (5) Sunlight incident on the greenhouse roof $\left(0\right.$ to $\left.20 \mathrm{~W} / \mathrm{m}^{2}\right)$; (6) Seasonal Cloudiness, which reduces the sun's radiation ( 0 to $100 \%$ ); (7) Wind speed (0 to $100 \mathrm{mph}$ ); (8) Wind direction with respect to the direction of the ventilation system of the greenhouse; (9) Measurement error of the sensing system (-4 to 4); (10) Change in Error of the measurement of the sensing system (-1 to 1$)$. 


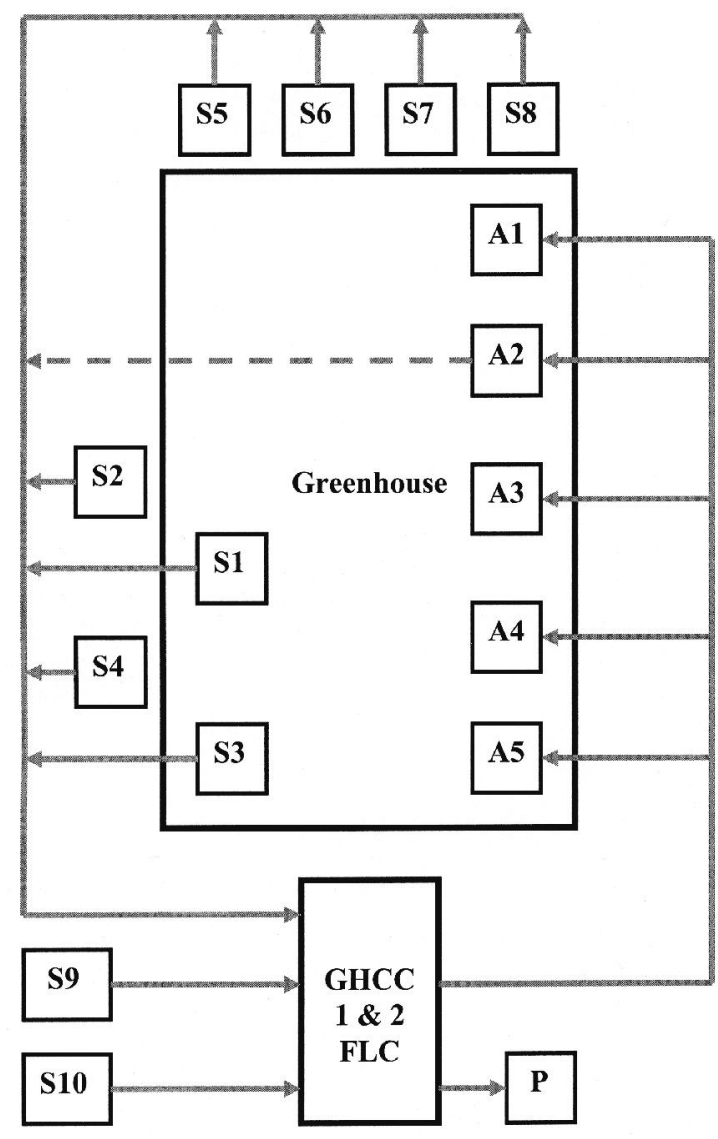

Notes: GHCC: Greenhouse climate controller; FLC: Fuzzy logic control; S1:Sensor recognizing the difference between, existing inside temperature of greenhouse \& optimum temperature that must be maintained in greenhouse $\left[{ }^{\circ} \mathrm{C}\right]$; S2: Sensor recognizing the difference between, existing outside temperature of greenhouse \& optimum temperature that must be maintained in greenhouse $\left[{ }^{\circ} \mathrm{C}\right]$; S3: Sensor recognizing the difference between, existing inside R-Humidity of greenhouse \& optimum R-Humidity that must be maintained in greenhouse [\%]; S4: Sensor recognizing the difference between, existing outside R-Humidity of greenhouse \& optimum R-Humidity that must be maintained in greenhouse [\%]; S5: Sensor sensing the sunlight incident on the greenhouse roof [W/m2]; S6:Seasonal Cloudiness which reduces the sun's radiation [\%]; S7: Wind speed [mph]; S8: Wind direction with respect to the direction of the ventilation system of the greenhouse; S9:

Measurement error of the sensing system; S10: Change in Error of the measurement of the sensing system; A1: Actuator system for thermal system; A2: Actuator system for ventilation \& humidification system; A3: Actuator system for Thermal shade system; A4: Actuator system for CO2 generation system; A5: Actuator system for forced ventilation system; P: Performance of the system.

Figure 4. Block diagram of the greenhouse controlling system.

The six outputs with range (universe of discourse) were: (1) Thermal system (0 to $100 \%$ ); (2) Ventilation and humidification system (0 to $100 \%$ ); (3) Thermal shade system (0 to $100 \%$ ); (4) $\mathrm{CO}_{2}$ generation system (0 to $100 \%$ ); (5) Forced ventilation system (0 to $100 \%$ ); (6) Performance of the system (0 to $100 \%)$.

In many fuzzy applications, the membership functions (MF) were arbitrarily selected as trapezoidal, triangular, or Gaussian depending upon the ranges selected (Ross, 1995). In this proposed model, the Gaussian membership function was used to define the input and output variable, because of its advantage of concise notation due to its smooth curve. The membership functions for the input and output variables were discussed in detail by A. Sriraman (Sriraman, 2003).

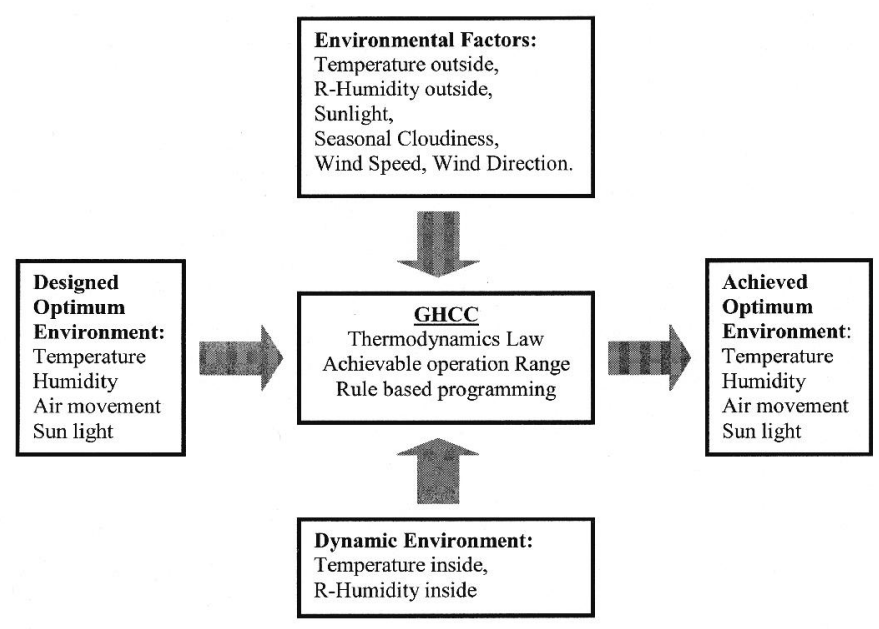

Figure 5. A functional block diagram of GHCC.

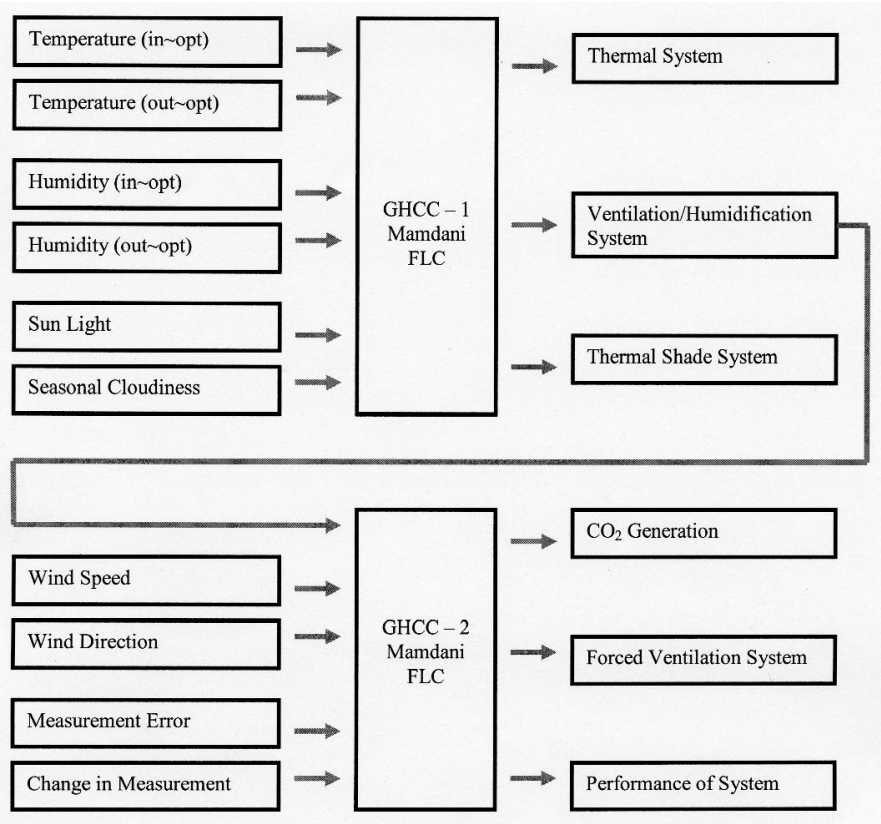

Figure 6. Role of FLP in GHCC.

\subsection{Fuzzification}

As described in Figure 7, fuzzification is the process of 
transforming the measured input values into fuzzy logic values. As an example in Figure 8, consider the input measurements $6.5{ }^{\circ} \mathrm{C}$ from the sensor $\mathrm{S} 1$ (senses the difference between inside and optimum temperature). The value $6.5^{\circ} \mathrm{C}$ intersects at the Positive and Positive High of the Temperature (in opt) membership set, with a $20 \%$ grade in Positive set and $80 \%$ grade in Positive High set. Similarly, consider the input measurement $12.5{ }^{\circ} \mathrm{C}$ from sensor $\mathrm{S} 2$ (senses the difference between outside and optimum temperature). The value 12.5 ${ }^{\circ} \mathrm{C}$ intersects at the Positive and Positive High of the Temperature (out opt) membership set, with a $20 \%$ grade in Positive set and $80 \%$ grade in Positive High set. While the Temperature (in opt) and Temperature (out opt) fuzzy set were intersected, the value of the Thermal system has a full $100 \%$ grade in the High Cooling set and $0 \%$ membership in rest of the set.

\section{INPUTS}
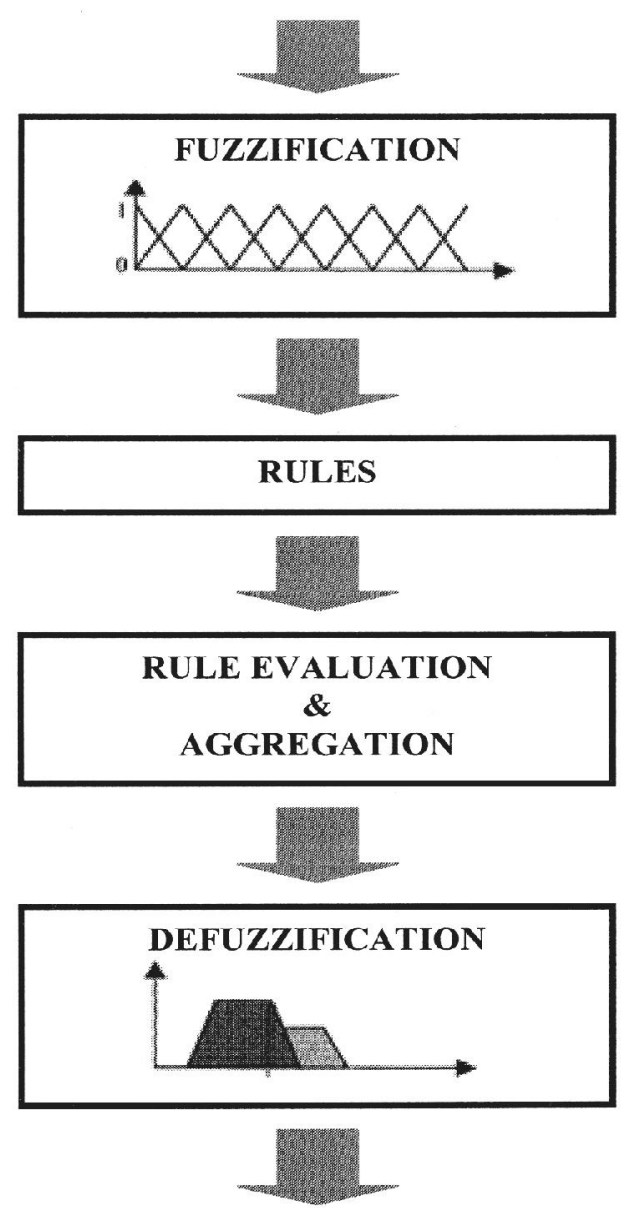

\section{OUTPUTS}

Figure 7. Steps in fuzzy logic program.

\subsection{Fuzzy Rules}

Instead of using crisp sets, such as actual numbers, fuzzy logic program permits the use of strings for writing rules.
There are five variables used in Temperature (in opt) and five variables in Temperature (out opt), which results in fifty rules with 11 output variables for Thermal System. The rules for the input and output of the fuzzy logic controller were discussed in detail by A. Sriraman (2003). Each rule consists of two antecedents connected by 'AND' operator, and a conclusion consisting of a single consequence for Thermal System. The antecedent expressions were replaced by membership grades $(\mu)$ through the fuzzification process. Since each input membership function was restricted to only two values $(\mu)$, a maximum combination of five rules could fire at a time.

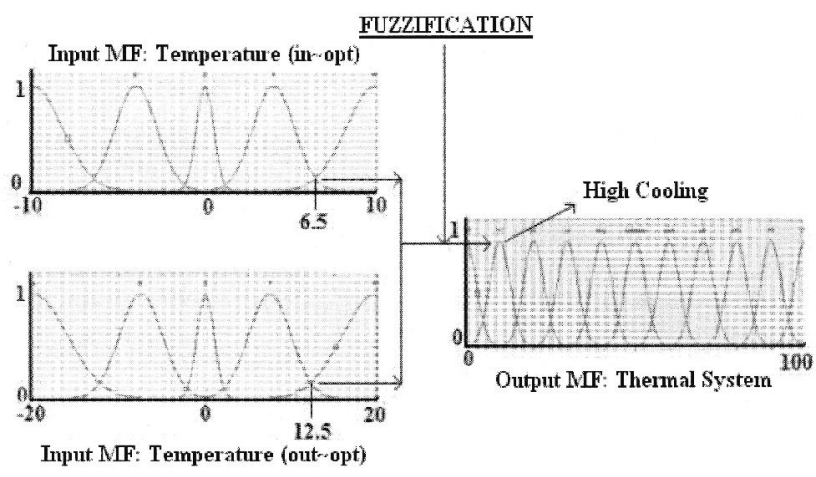

Figure 8. Example of fuzzification process.

\subsection{Rule Evaluations and Aggregation}

The MIN-MAX inference method was used to determine output values from rules satisfied during the evaluation process. The consequent fuzzy union is restricted to the minimum of the predicate truth, while the output fuzzy region is updated by taking the maximum of the minimized fuzzy sets. The minimum operator limits certainty of the overall condition to the least certain input observation. The final output membership function was obtained using the MAX composition procedure.

\subsection{Defuzzification}

The Mean of Maximum (MOM) defuzzification method was used and it takes the mean value of the set with maximum membership grade, given as:

$M O M=\bar{y}=\frac{\sum_{j=1}^{n} y_{j}}{n}$

\section{Interface for GHCC}

The proposed intelligent climate controller must be judged on the basis of its ability to infer, from a set of given inputs, with that of an expert in greenhouse management area. Based on this concept the controller must be tested for reliability for several values of inputs. An interface was built using MATLAB Graphical User Interface software tool. The frame of the graphical user interface was shown in Figure 9. The user can vary the value of one or more input variable simul- 
taneously and can see the effect of the inputs on the outputs with this graphical user interface.

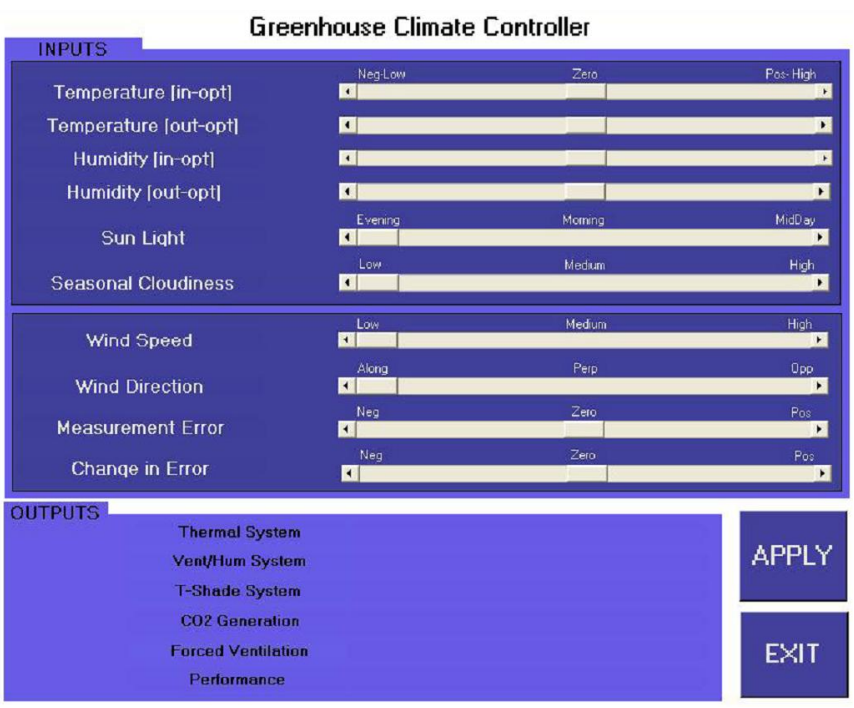

Figure 9. Interface for greenhouse climate control.

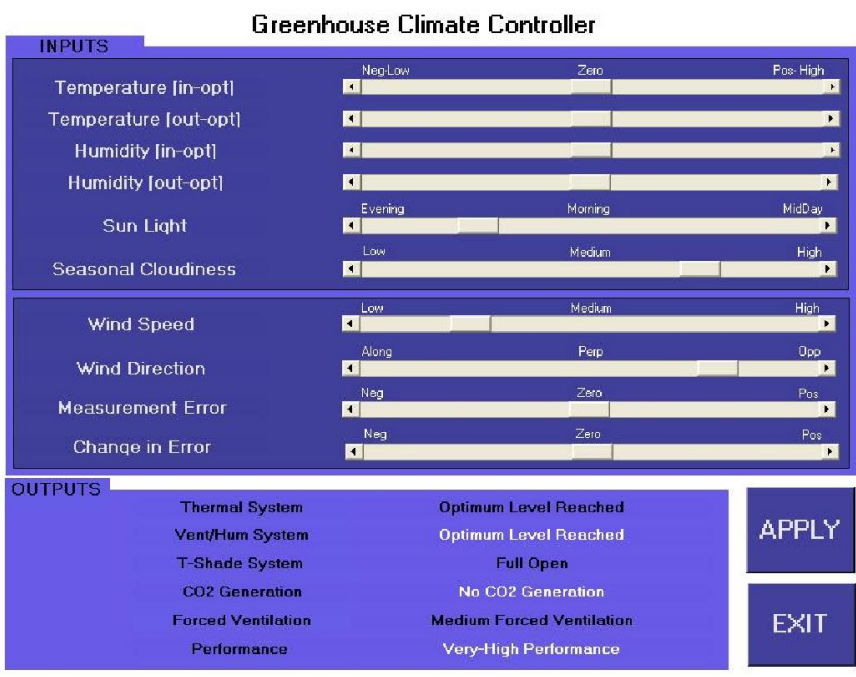

Figure 10. Sample result.

\section{Result}

Every input variable was tested thoroughly by increasing and decreasing the values in between maximum and minimum position in the graphical user interface to understand how the proposed intelligent greenhouse climate controller works. An example simulation result shown in figure 10, where different input values such as sunlight, seasonal cloudiness, wind speed, wind direction were manipulated, to observe the corresponding outputs in the actuator systems.

\section{Conclusion}

The proposed fuzzy logic control technique for the green- house climate controller has the following advantages:

1) In the GUI, the user can simply vary the climate change (input) to see the immediate effect (output) of the control of the greenhouse climate control system. The results show that the proposed fuzzy logic program performs quickly to control the greenhouse climate control system.

2) The controller program is based on fuzzy logic program with rule base; therefore it is simple to design the control program for any kind of greenhouse climate.

3) The controller program can be modified and applied for any existing greenhouse application, as the design is very simple and the program is highly adaptable for any platform of operating system.

4) The program takes only a few kilo bytes of memory space. Hence this has a high advantage over a program that takes a lot of memory space.

Acknowledgments. This study is funded by the National Natural Science Fund of China (70273005) and the National Key Basic Research and Development Plan projects (2006CB403403).

\section{References}

Al-Faraj, A., Meyer, G.E., and Horst, G.H. (2001). A crop water stress index for tall fescue (Festuca arundinacea Schreb.) irrigation decision-making - a fuzzy logic method, Comput. Electron. Agric., 32, 69-84.

Arbel, A., Barak, M. and Shklyar, A. (2003). Combination of forced ventilation and fogging systems for cooling greenhouses, Biosys. Eng., 84, 45-55.

Baker, J.C. (1990). Effects of day and night humidity on yield and fruit quality of glasshouse tomatoes (Lycoperscon esculentum Mill.), J. Hortic. Sci., 65, 323-331.

Caponetto, R., Fortuna, L., Nunnari, G., Occhipinti, L. and Xibilia, M. G. (2000). Soft computing for greenhouse climate control, IEEE Transaction on Fuzzy Systems, 8 (6), 753-760.

Collewet, C., Rault, G., Quellec, S. and Marchal, P. (1998). Fuzzy adaptive controller design for the joint space control of an agricultural robot, Fuzzy Sets and Systems, 99 (1), 1-25.

Ferreira, P.M., Faria, E.A., and Ruano, A.E. (2002). Neural network models in greenhouse air temperature prediction, Neurocomputing, $43,51-75$.

Giacomelli, G.A. and Roberts, W.J. (1993). Greenhouse Covering Systems, HortTechnol., 3, 50-58.

Joliet, O. (1994). HORTITRANS, a model for predicting and optimizing humidity and transpiration in greenhouse, J. Agric. Eng., 57 (1), 23-37.

Joliet, O. and Bailey, B.J. (1992). The effect of climate on tomato transpiration in greenhouses: measurement and models comparison, Agric. For. Meteorol., 58, 43-62.

Körner, O. and Challa, H. (2003). Process-based humidity control regime for greenhouse crops, Comput. Electron. Agric., 39 (3), 173 $-192$.

Lefas, C.C. and Santamouris, M.J. (1985). Application of microcomputers in optimal greenhouse environmental control and resource management, Solar and Wind Technology, 1 (3), 153-160.

Morimoto, T. and Hashimoto, Y. (2000). An intelligent control for greenhouse automation, oriented by the concept of SPA and SFA an application to a post-harvest process, Comput. Electron. Agric., 29 (1-2), 3-20. 
Pasgianos, G.D., Arvanitis, K.G., Polycarpou, P. and Sigrimis, N. (2003). A nonlinear feedback technique for greenhouse environmental control, Comput. Electron. Agric., 40 (1-3), 153 - 177.

Papadoupolos, A.P. (1991). Growing greenhouse tomatoes in soil and in soil less media, Agriculture Canada Publication, Publication No. 1865.

Ross, T.J. (1995). Fuzzy logic with engineering applications. McGraw-Hill, New York, USA, 1995.

Seginer, I. and Zlochin, I. (1997). Night-time greenhouse humidity control with a cooled wetness sensor, Agric. For. Meteorol., 85, 269-277.

Seginer, I., Willits, D.H., Raviv, M. and Peet, M.M. (1997). Transpirational cooling of greenhouse crops, 1st Annual Report to the U.S.-Israel Binational Agricultural Research and Development Fund, BARD Project No.IS-2538-95R.

Stanghellini, C. and De Jong, T. (1995). A model of humidity and its applications in a greenhouse, Agric. For. Meteorol., 76 (2), 129148.
Sriraman, A. (2003). An intelligent system approach for greenhouseclimate control, Masters of Engineering Project Report, University of Regina, Regina, SK, Canada.

Straten, G.V. (1999). Acceptance of optimal operation and control methods for greenhouse cultivation, Annual Reviews in Control, 23, 83-90.

Teitel, M., Segal, I., Shklyar, A. and Barak, M. (1999). A comparison between pipe and air heating methods for greenhouses, J. Agric. Eng., 72, 259-273.

Willits, D.H. and Peet, M.M. (1993). The effect of evaporative cooling on the efficiency of external greenhouse shade cloths, Paper No. 93-4042, ASAE Meeting Presentation, Spokane, Washington, USA.

Willits, D.H. and Peet, M.M. (1989). Predicting yield responses to different greenhouse $\mathrm{CO} 2$ enrichment schemes: cucumbers and tomatoes, Agric. For. Meteorol., 44 (3-4), 275-293.

Zimmerman, H.J. (1990). Fuzzy set theory and its applications, Kluwer Academic Publishers, 2nd edition. 